\title{
VALIDATION OF ROAD LOAD CHARACTERISTIC OF A SUB-COMPACT VEHICLE BY ENGINE OPERATION
}

\author{
Devarajan Ramasamy ${ }^{2}$, Goh Chin Yuan ${ }^{1}$, Rosli Abu Bakar ${ }^{2}$ and Z.A Zainal ${ }^{1}$ \\ ${ }^{1}$ USM School of Mechanical Engineering, \\ Engineering Campus, Universiti Sains Malaysia, Seri Ampangan, 14300 NibongTebal, \\ Seberang Perai Selatan, Pulau Pinang, Malaysia. \\ ${ }^{2}$ Mechanical Engineering Faculty, \\ Universiti Malaysia Pahang \\ 26600 Pekan, Pahang, Malaysia \\ Email: deva@ump.edu.my Phone: 0167580946
}

\begin{abstract}
Vehicle efficiency relates to pollutants and cost savings in third world countries. In terms of sub-compact cars, the vehicle characteristics are governed by the engine and road load characteristics. The main objective was to evaluate the coefficients of rolling resistance and drag on a moving sub-compact car and to compare the results from engine tests on a dynamometer. Tests were conducted on a local sub-compact car to measure engine speed, throttle position and air fuel ratio while Global Positioning Systems (GPS) recorded data of the vehicle's speed and position. Also, dynamometer testing was carried out to determine the vehicle characteristics. The results of an on the road roll down test and cruising test were combined to get the road load characteristics of the vehicle. A comparison of the road loads obtained with the actual engine dynamometer test was found to have about 5\% error. The experimental errors show the validation of the tests. The tests show the dynamometer's relation to real life road loads.
\end{abstract}

Keywords: Dynamometer; road loads; onboard measurement;vehicle speed.

\section{INTRODUCTION}

A sub-compact vehicle is a vehicle which has between 2407L and 2803L of interior volume, according to the US Environmental Protection Agency (Wu, Zhao, \& Ou, 2011). Usually it has a length of $4191 \mathrm{~mm}$ but is longer than a micro car. Such cars are usually popular in South-East Asia. This is because in the majority of that region people live in cities and require a small and highly manoeuvrable vehicle without compromising interior volume. Normally a sub-compact vehicle is powered by an internal combustion engine. Internal combustion engines rely on fossil fuel such as gasoline and diesel(Ghobadian, Najafi, \& Nayebi, 2013; Mat Yasin, Mamat, Sharma, \& Yusop, 2012; Rahim, Mamat, Taib, \& Abdullah, 2012). Fossil fuels are a nonrenewable form of energy, which implies that there is a finite amount in the world(Azad, Ameer Uddin, \& Alam, 2012; Aziz Hairuddin, Wandel, \& Yusaf, 2013; Soon, Rus, Anika, \& Hasan, 2013; Sundar Raj \& Sendilvelan, 2010; Yusaf, Hamawand, Baker, \& Najafi, 2013). Also, when fossil fuel burns it produces pollutants including carbon dioxide which contributes to the greenhouse effect, and nitrous oxide which contributes to acid rain (Johnstone \& Karousakis, 1999). Therefore the study of vehicle efficiency is important. Vehicle efficiency is governed by the engine of the 
vehicle and the road load characteristics acting on the vehicle itself. As found by (Tzirakis, Pitsas, Zannikos, \& Stournas, 2006), the relation between fuel consumption and vehicle track can be measured by Global Positioning Satellites (GPS). GPS technology is a preferred method of measurement because of its ability to accurately determine position and speed using signals from orbiting satellites (Smith, Morison, Capelle, Christie, \& Blair, 2011). Similar tests were carried out by Durell, Allen, Law, and Heath (2000) of the Argonne National Laboratory to evaluate two hybrid electric vehicles both on the road and using a dynamometer for their fuel economy, battery characteristics, engine operation, and overall hybrid control strategy. The results of these tests enable realistic conditions to be simulated on a dynamometer. In this paper the author will concentrate more on the vehicle road load characteristics for a subcompact car in Malaysia. A correlation between transient vehicle loads and tests on a dynamometer was found. The test can be used in future to determine the driving patterns on the road for the average passenger car in Malaysia and their individual driving cycles.

\section{ROAD LOAD CHARACTERISTIC}

The road load characteristic is a formula that describes the vehicle power required to cruise at a certain speed. This power is used to overcome the rolling resistance which comes from the friction of tires and aerodynamic drag of the vehicle. The road load characteristic of a vehicle is governed by Eq.1 (Heywood, 1988):

$$
P_{r}=\left(C_{R} M_{v} g+\frac{1}{2} \rho_{a} C_{D} A_{v} S_{v}^{2}\right) S_{v}
$$

where

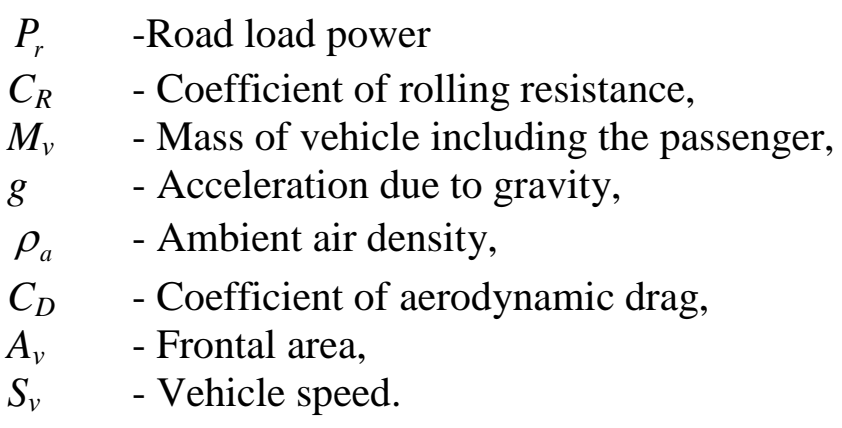

As shown in the formula, the rolling resistance of the vehicle is influenced by the coefficient of rolling resistance, $C_{R}$ and the mass of the vehicle, $M_{v}$. Also, the aerodynamic resistance is influenced by the coefficient of drag, $C_{D}$, the vehicle frontal area, $A_{v}$ and the vehicle speed, $S_{v}$. At low speed cruising, the rolling resistance of the vehicle consumes more power than the aerodynamic resistance. However, at high speed cruising, the aerodynamic resistance consumes more power than the rolling resistance. The effect is seen in Figure 1 by Moore, Rahman, and Ehsani (1999). The road load data also enables the estimation of the energy demand of the engine or power plant. According to Smith et al. (2011), the engine energy is the sum of opposing forces on the vehicle, as given in Eq. 2:

$$
E_{\text {engine }}=\sum_{t=0}^{t_{n}}\left(P_{r}\right)
$$




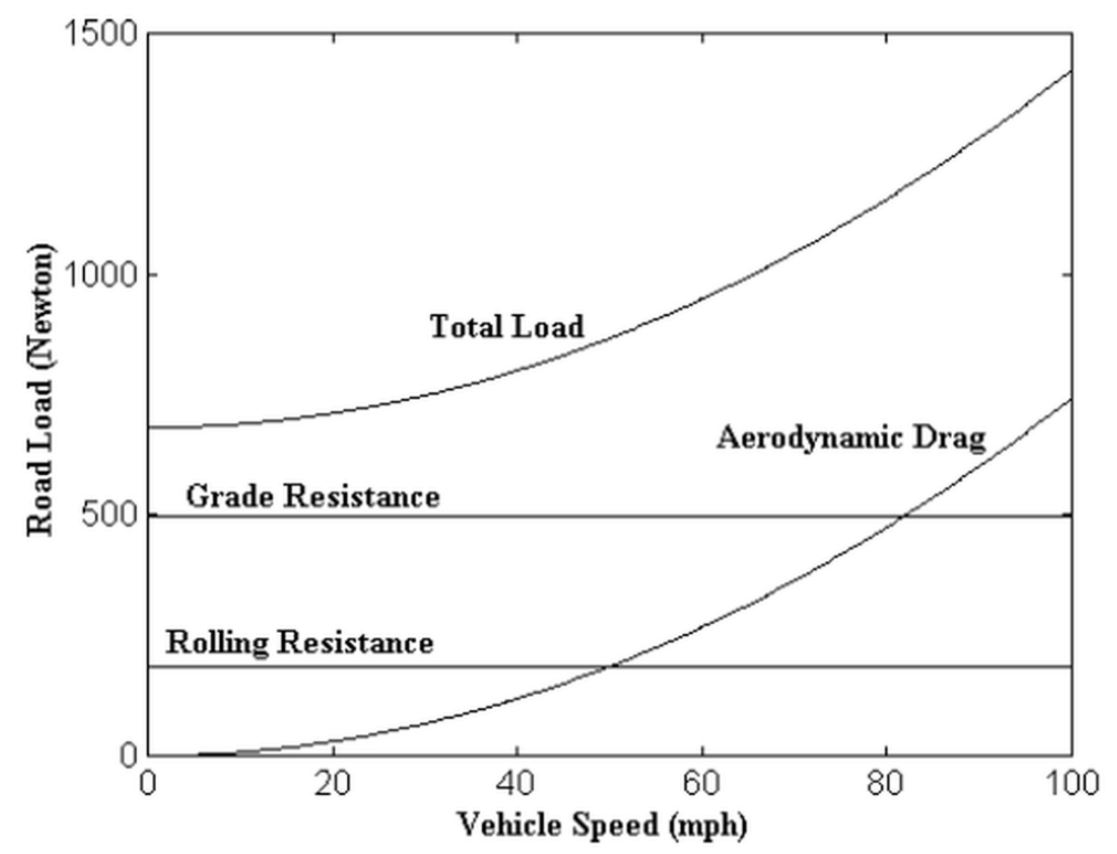

Figure 1. Typical vehicle load function(Moore et al., 1999)

\section{TEST VEHICLE}

The vehicle chosen for testing is a sub-compact car from Malaysia and is shown in Figure 2. The specification of the vehicle is as stated in Table 1(DMC, 2012). The specification for the car's engine and transmission is shown in Tables 2 and 3.

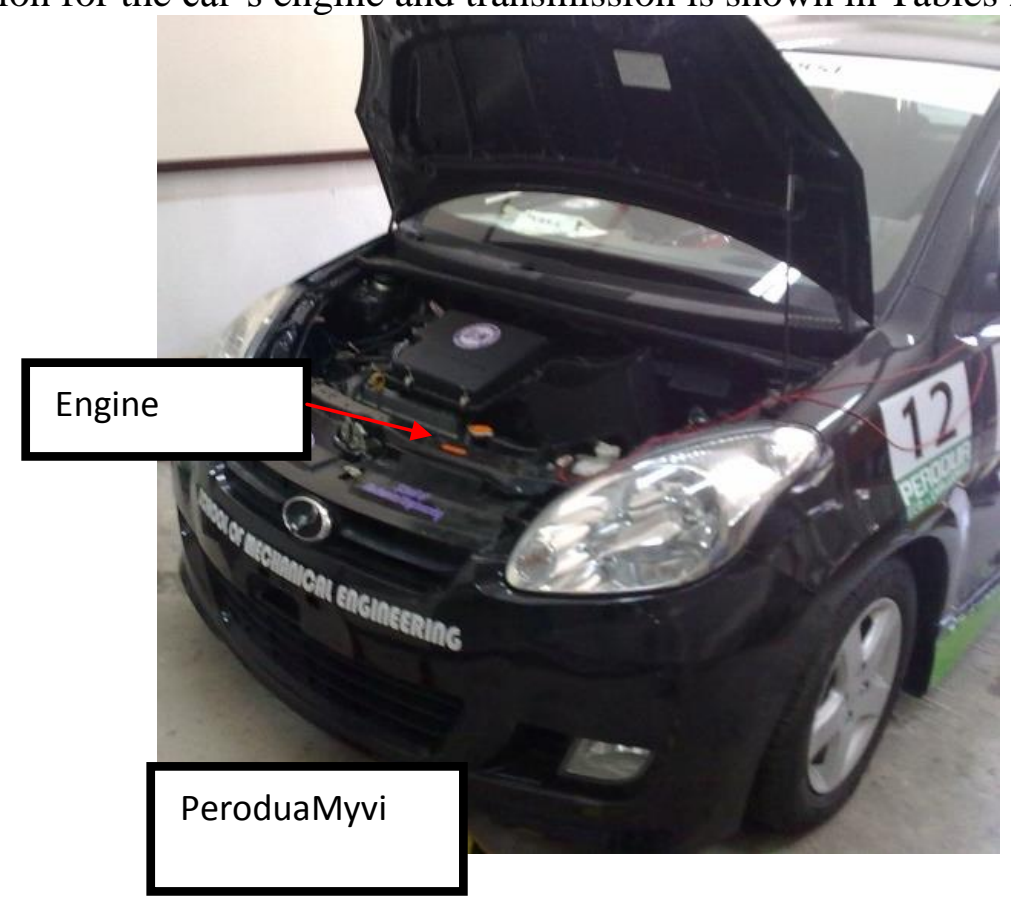

Figure 2.Sub-compact local car in Malaysia 
Table 1. Vehicle specification

\begin{tabular}{lc}
\hline Parameter & Dimensions \\
\hline Overall length/width/height $(\mathrm{mm})$ & $3690 / 1665 / 1545$ \\
Wheelbase $(\mathrm{mm})$ & 2440 \\
Track front/rear $(\mathrm{mm})$ & $1455 / 1465$ \\
Tyres $(\mathrm{mm})$ & $175 / 65 \mathrm{R} 14$ \\
Weight (with 2 persons) $(\mathrm{kg})$ & 870 \\
Seating capacity (persons) & 5 \\
\hline
\end{tabular}

Table 2. Engine specification

\begin{tabular}{lc}
\hline Parameter & Specification \\
\hline Engine type & K3-VE \\
& DOHC, 16V with \\
Valve mechanism & DVVT \\
Total displacement & $1298 \mathrm{cc}$ \\
Bore X stroke & $72.0 \times 79.7 \mathrm{~mm}$ \\
Compression ratio & $10.0: 1$ \\
Maximum power output & $67 / 6000 \mathrm{~kW} / \mathrm{rpm}$ \\
Maximum torque output & $117 / 4400 \mathrm{Nm} / \mathrm{rpm}$ \\
& Electronic fuel \\
Fuel system & injection \\
\hline
\end{tabular}

Table 3. Transmission specification

\begin{tabular}{lr}
\hline Automatic transmission & Gear ratio \\
\hline 1st & 2.731 \\
2nd & 1.526 \\
3rd & 1.000 \\
4th & 0.696 \\
Final reduction & 4.032 \\
\hline
\end{tabular}

\section{THE TRACK}

The tracks chosen for testing are shown in Figure 3. The location is on the Universiti Sains Malaysia, Engineering Campus in Penang, Malaysia. These tracks are flat and thus minimize the effects of inclination on the results. As found by (Shimizu, Ikeya, \& Miyagi, 1988), inclination can have as much as $10 \%$ effect on the fuel consumption for each 1 degree increase. The maximum cruising speed for track 1 was determined as $60 \mathrm{~km} / \mathrm{hr}(16.67 \mathrm{~m} / \mathrm{s})$ and for track 2 is $80 \mathrm{~km} / \mathrm{hr}(22.22 \mathrm{~m} / \mathrm{s})$. 


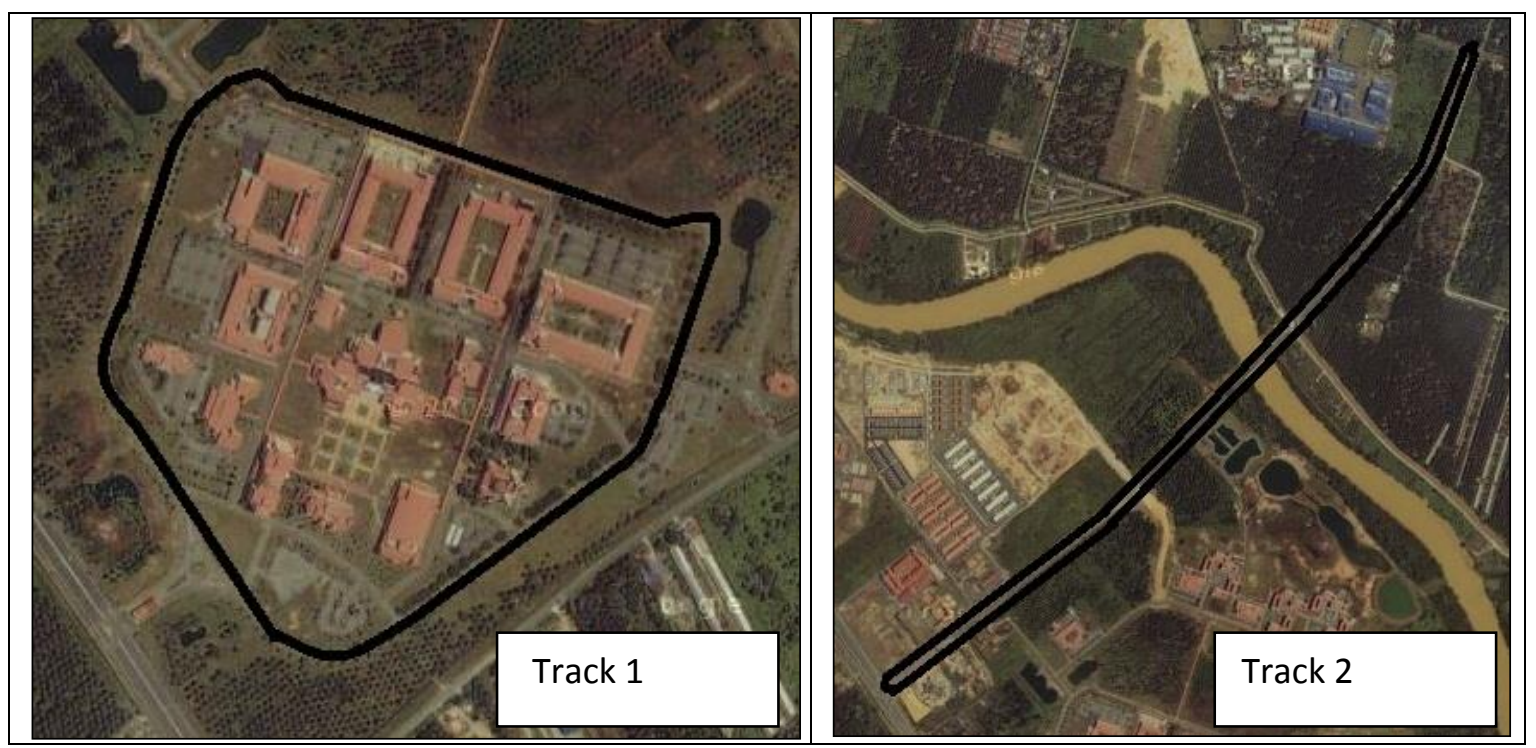

Figure 3. Tracks1 and 2

\section{VEHICLE INSTRUMENTATION}

The vehicle was instrumented with a data acquisition system which records the engine speed, throttle position and air fuel ratio. The acquired data was saved in a computer for further processing during the test. Meanwhile, to record the moving vehicle, GPS was used to record the vehicle's dynamics, variable of position and speed, as found by (Wu et al., 2011). Figure 4 shows the schematic of the vehicle instrumentation.

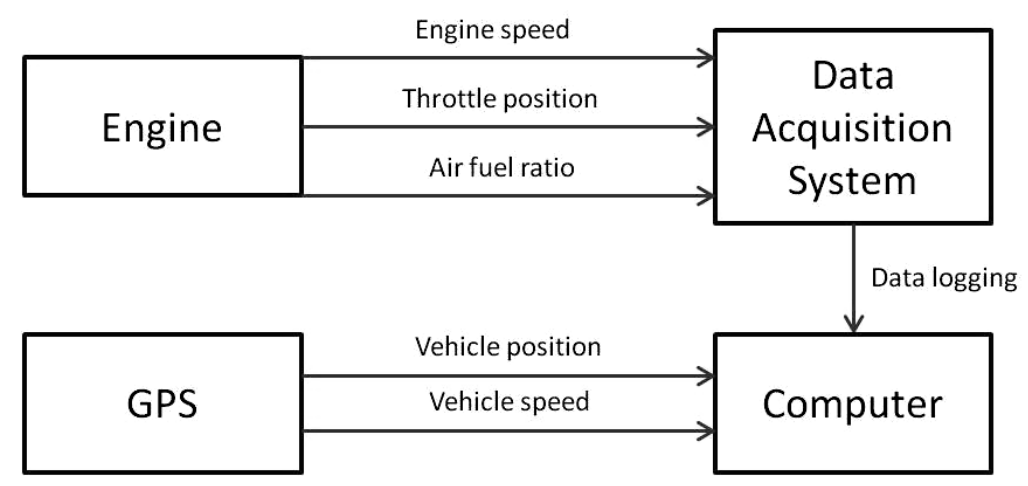

Figure 4. Vehicle instrumentation schematic

\section{ROLL DOWN TEST}

In the roll down test, the vehicle was accelerated to about $70 \mathrm{~km} / \mathrm{hr}$ on track 1 . Once the vehicle reached the targeted speed, it was left to roll in neutral gear until it came to a stop. For both rolling resistance and drag in this case it was assumed that the wind effect could be neglected in the test, as found by (Roussillon, 1981). When the vehicle started to roll, the vehicle speed was recorded using GPS. This process was repeated to minimize the influence of wind on the data collected. With the data obtained from the roll down test, a road load power curve was generated. 


\section{CRUISING TEST}

In the cruising test, the vehicle was moving at a constant speed, and the speeds recorded were $10 \mathrm{~km} / \mathrm{hr}, 20 \mathrm{~km} / \mathrm{hr}$, etc. When the vehicle reached the desired constant speed, the engine speed, throttle position and air fuel ratio were recorded with a data acquisition system. The maximum cruising speed of the vehicle on track 1 was $60 \mathrm{~km} / \mathrm{hr}$ and on track $280 \mathrm{~km} / \mathrm{hr}$. The important parameters are the engine speed and throttle position. The air fuel ratio values were used to do a cross-check when the engine was on an engine dynamometer.

\section{ENGINE DYNAMOMETER}

After the roll down test and cruising test, the engine in the vehicle was taken out and put on an engine dynamometer with all the engine systems intact as per the manufacturer's specification. Data from the cruising test was used to operate the engine at conditions similar to those used on the road tests at the given speeds. The data from the engine dynamometer, such as engine speed and torque, were recorded using the data acquisition system. Figure 5 shows a schematic of the engine dynamometer. The collected data was then processed to generate an actual road load power graph, which was then compared with the data collected from GPS.

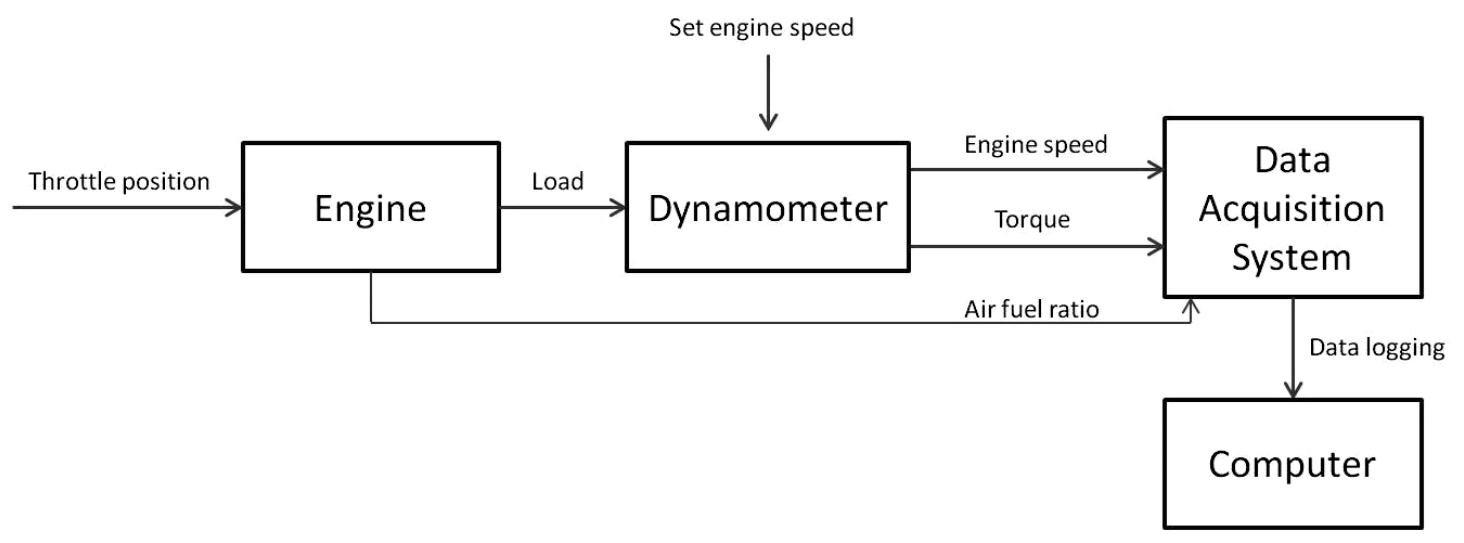

Figure 5. Engine dynamometer schematic

\section{RESULTS AND DISCUSSION}

All the data was processed in a spreadsheet. Figure 6 shows the raw data obtained for all the tests carried out. The data was filtered for the best points and six of the tests were examined further. As seen in Figure 6, all the data show good correlation with each test. The curves peak when the vehicle is accelerating and dip when the vehicle is decelerating. To determine the best experiment points for each case, curve fitting of the data was done. Table 4 shows the constant values used for the curve matching of the road load. Figure 7 shows the comparison between the raw experimental data and the curve fitting. A total of seven tests were conducted to obtain the drag and rolling coefficients. 


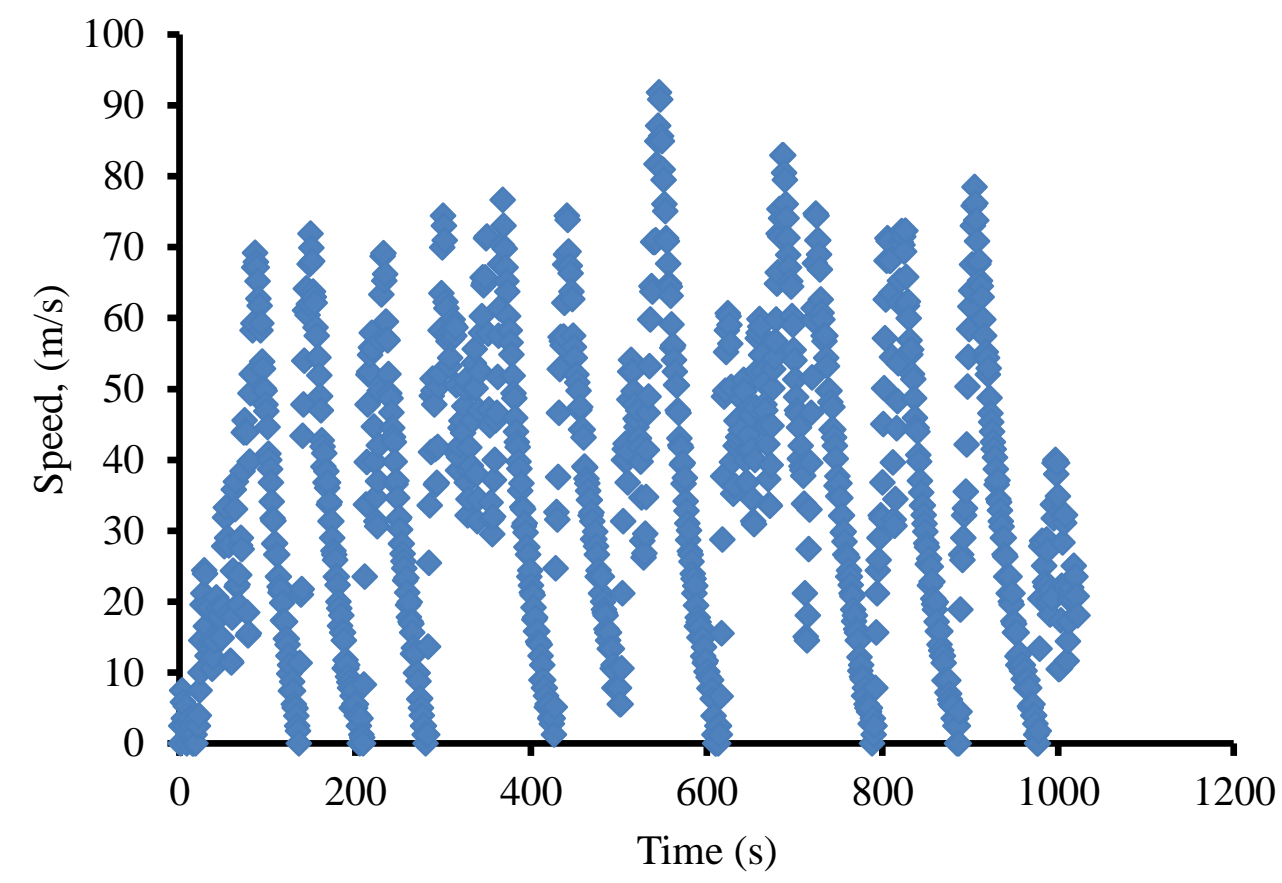

Figure 6. Data taken from the roll down test

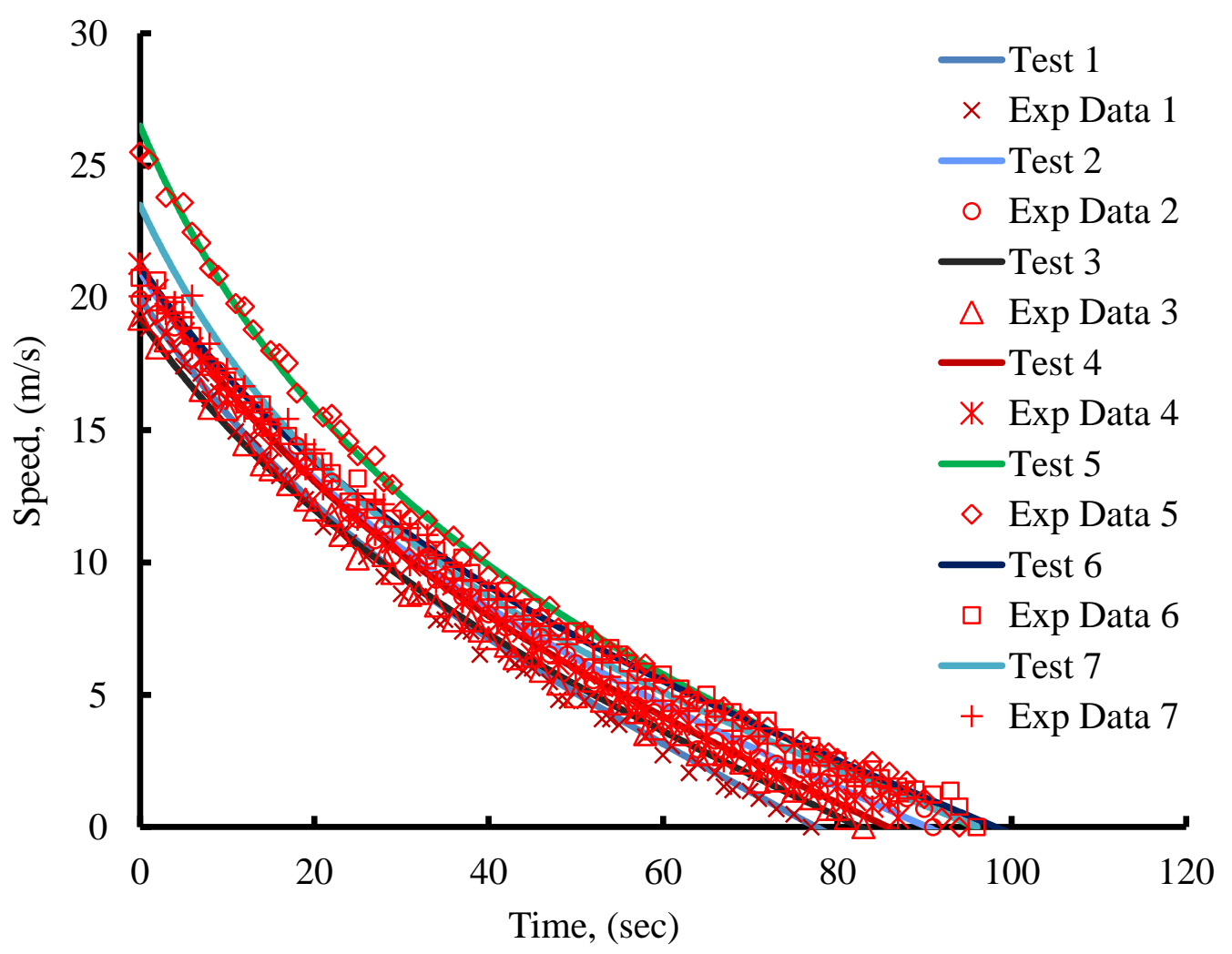

Figure 7. Experimental roll down tests conducted on track

The curve matching was done using Eq. 1, in which the coefficients of drag and rolling resistance values were obtained once the experimental graph coincided with the curve fitting. Once the values of the coefficients of drag and rolling resistance matched 
the GPS data, the variables were recorded. Table 5 shows the values of the coefficients of drag and rolling resistance for each test recorded from Figure 7. By using the overall averaged data for $C_{D}$ and $C_{R}$ at each test point, the simulated road power values can be plotted, as shown in Figure 8. The trend of Figure 8 matches perfectly with Figure 1's theoretical data based on Eq. 1. A maximum load of $32.2 \mathrm{~kW}$ was obtained at $120 \mathrm{~km} / \mathrm{h}$ and it follows the quadratic form due to the square of velocity, $S_{v}$.

Table 4. Constants used in the equation

\begin{tabular}{lrl}
\hline Constants & Values & \\
\hline Mass of the vehicle including people onboard & 870 & $\mathrm{~kg}$ \\
Acceleration of gravity & 9.81 & $\mathrm{~m} / \mathrm{s}^{2}$ \\
Air density & 1.14 & $\mathrm{~kg} / \mathrm{m}^{3}$ \\
Frontal area of vehicle & 2.6 & $\mathrm{~m}^{2}$ \\
\hline
\end{tabular}

Table 1. Coefficients of rolling resistance and drag from roll down test

\begin{tabular}{lcc}
\hline Test number & Coefficient of rolling resistance, $C_{R}$ & Coefficient of drag, $C_{D}$ \\
\hline Test 1 & 0.49 & 0.0180 \\
Test 2 & 0.50 & 0.0150 \\
Test 3 & 0.50 & 0.0160 \\
Test 4 & 0.52 & 0.0160 \\
Test 5 & 0.52 & 0.0155 \\
Test 6 & 0.45 & 0.0140 \\
Test 7 & 0.45 & 0.0135 \\
\hline Average & 0.490 & 0.0154 \\
\hline
\end{tabular}

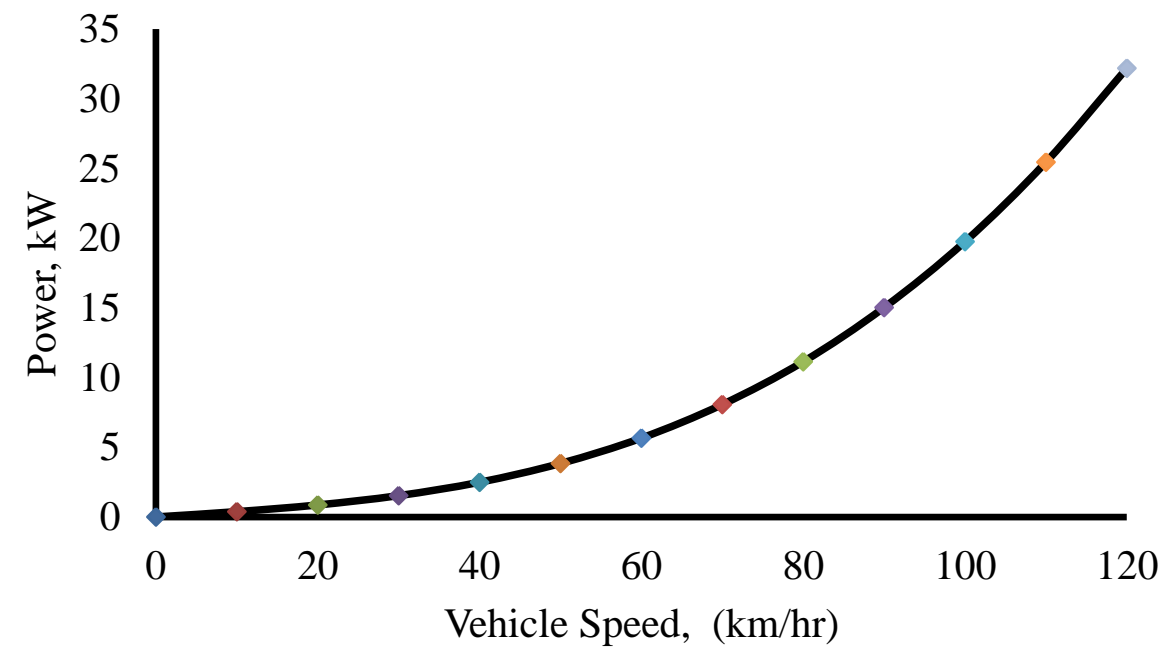

Figure 8. Simulated road power using average data from roll down test

After the simulated data was obtained from Figure 8, an experiment to mimic road load conditions in real life was carried out. The load value was obtained from the TPS position of the vehicle travelling at a constant speed. The values were obtained 
together with the vehicle gear settings for each speed. Table 6 shows the values of gear position and throttle position at specific vehicle speeds obtained from the cruising tests on tracks 1 and 2. The engine speed was calculated by using the gear ratio found in Table 3 and the throttle position sensor (TPS) signal from the engine. The values were then used as dynamometer settings to find the real loads on the engine. This was done using the data from Table 6,andthe value of torque and engine speed was recorded for each case. A plot of the power required curve for the dynamometer was made.

Table 6. Data from engine vehicle testing and dynamometer

\begin{tabular}{cccccc}
\hline & \multicolumn{3}{c}{ Vehicle testing } & \multicolumn{2}{c}{ Dynamometer } \\
\hline $\begin{array}{c}\text { Vehicle speed } \\
(\mathrm{km} / \mathrm{hr})\end{array}$ & $\begin{array}{c}\text { Engine speed } \\
(\mathrm{RPM})\end{array}$ & Gear & $\begin{array}{c}\text { TPS } \\
(\mathrm{V})\end{array}$ & $\begin{array}{c}\text { Torque } \\
(\mathrm{Nm})\end{array}$ & $\begin{array}{c}\text { Power } \\
(\mathrm{kW})\end{array}$ \\
\hline 10 & 1100 & 1 & 0.62 & 4.0 & 0.46 \\
20 & 1300 & 2 & 0.67 & 6.0 & 0.82 \\
30 & 1200 & 3 & 0.65 & 9.5 & 1.19 \\
40 & 1600 & 3 & 0.70 & 13.1 & 2.19 \\
50 & 1400 & 4 & 0.75 & 23.2 & 3.40 \\
60 & 1700 & 4 & 0.82 & 27.6 & 4.91 \\
70 & 2000 & 4 & 0.89 & 37.7 & 7.90 \\
80 & 2300 & 4 & 0.95 & 45.0 & 10.84 \\
\hline
\end{tabular}

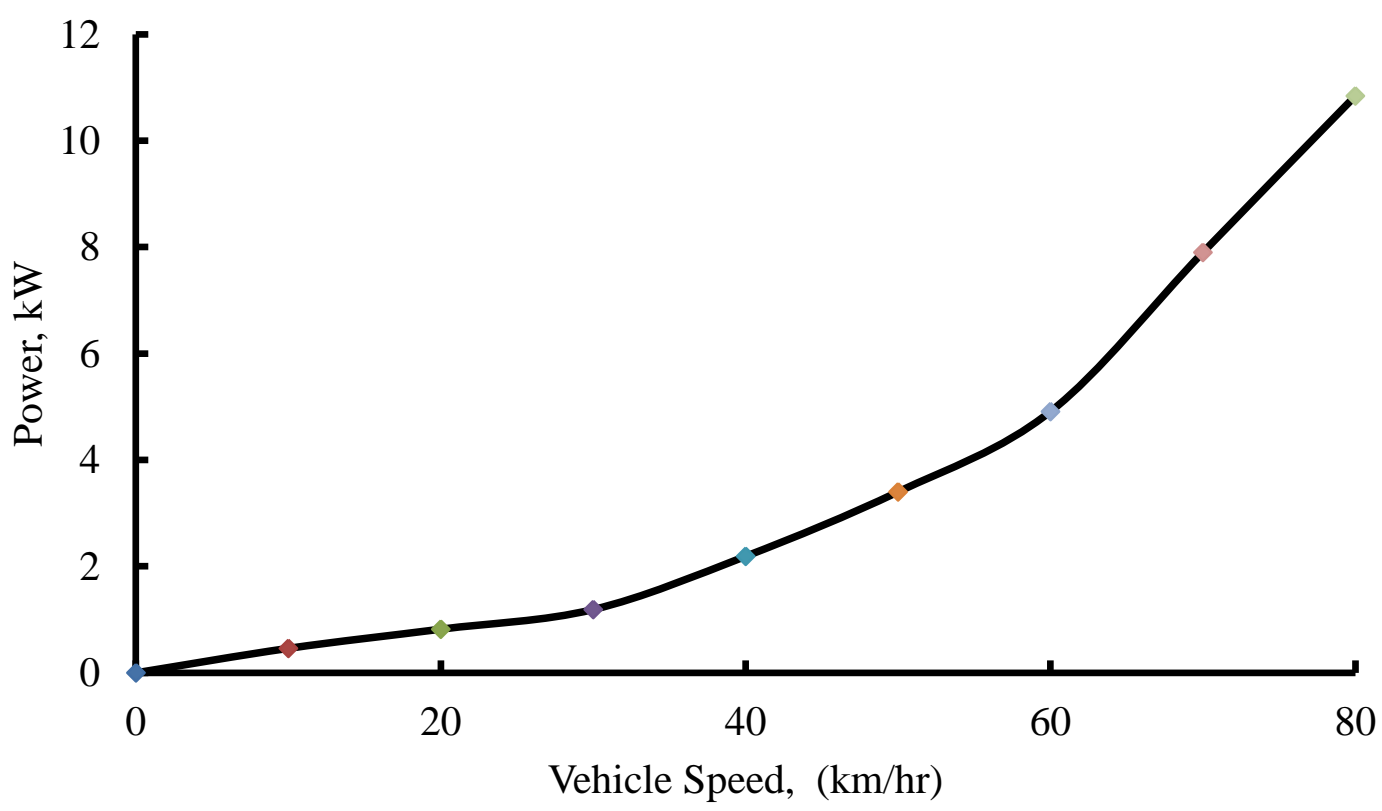

Figure 9. Road power from engine dynamometer data

Figure 9 shows the graph of road power as measured by the dynamometer. A maximum of $10.84 \mathrm{~kW}$ was obtained at $80 \mathrm{~km} / \mathrm{h}$. When compared to Figure $8,80 \mathrm{~km} / \mathrm{h}$ was calculated as $11.14 \mathrm{~kW}$. As such, a loss of $2.7 \%$ occurred. This error reading of the theoretical and experimental data was considered small and in the acceptable region, as found by (Roussillon, 1981) where 5-15\% model and experiment deviation was 
acceptable. Figure 10 shows the theoretical simulated data with the experimental engine operation data. The data shows a good relationship with the engine operation data. Overall, the theoretical data shows slightly higher power than the experiment on the dynamometer. A 5\% error bar allotted to Figure 15 shows good fitting from both the experiment with the dynamometer and the theoretical model from Eq.1. The error occurred only at midrange speed in the experiments, that is, from 30 to $70 \mathrm{~km} / \mathrm{hr}$. At higher speeds, the higher forces seem to equal the dynamometer results. However, at the slow speed of $10 \mathrm{~km} / \mathrm{hr}$ the reading deviated due to higher fluctuation as the engine speed was near idling. The theoretical assumption should give a more positive reading, due to some unavoidable systematic errors in the experiments. This may occur as the result of any slight inclination of the road which was ignored earlier in the calculation. The heating and cooling in the transient road load may also cause this small difference, since the dynamometer only considers one setting for the temperature value.

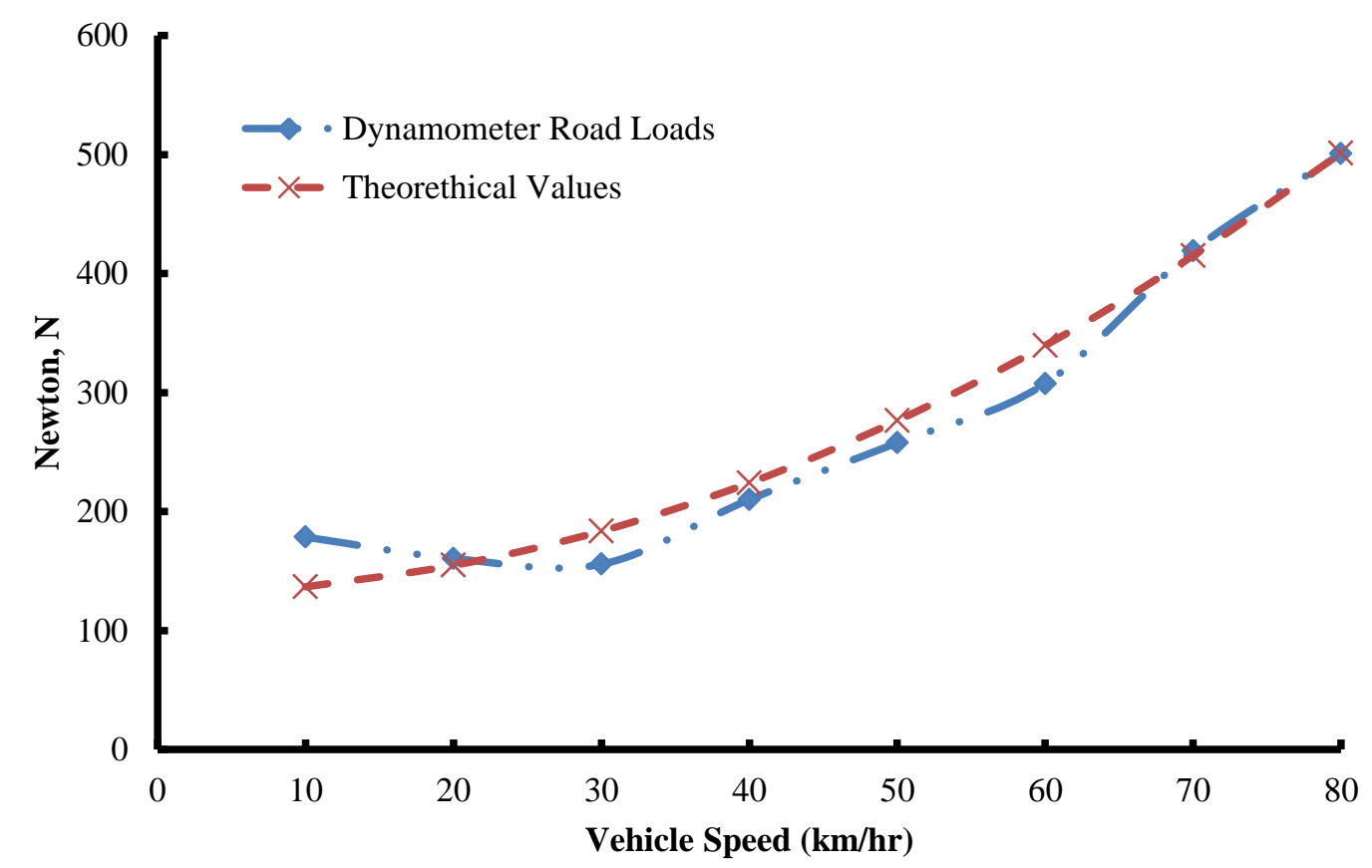

Figure 10. Road load data comparison between data from roll down test and engine dynamometer

\section{CONCLUSIONS}

The vehicle characteristics such as the coefficient of rolling resistance and coefficient of drag can be predicted by using GPS. The data can then be validated with engine operations using a dynamometer. With these coefficients known, it is possible to simulate the road load power demand on an engine dynamometer. For this dynamometer, a compensation of $5 \%$ error may be required when the final results of the simulation and experiments are compared. The results will enable road loads to be simulated on a dynamometer with minimal errors. 


\section{ACKNOWLEDGMENTS}

The authors would like to thank the Faculty of Mechanical Engineering in Universiti Sains Malaysia (USM) and MOSTI for financial support under MOSTI Science Fund (Optimization of Combustion for Compressed Natural Gas (CNG) Fuel Engine: 6013388).

\section{REFERENCES}

Azad, A. K., Ameer Uddin, S. M., \& Alam, M. M. (2012). A comprehensive study of di diesel engine performance with vegetable oil: An alternative boi-fuel source of energy. International Journal of Automotive and Mechanical Engineering, 5, 576-586.

Aziz Hairuddin, A., Wandel, A. P., \& Yusaf, T. (2013). Effect of different heat transfer models on a diesel homogeneous charge compression ignition engine. International Journal of Automotive and Mechanical Engineering, 8, 12921304.

DMC. (2012). Daihatsu motor company ltd. Annual report 2011, EPPO Bulletin.

Durell, E., Allen, J., Law, D., \& Heath, J. (2000). Installation and development injection system for a bi-fuel gasoline and compressed natural gas engine. Paper presented at the Proc. of 7th International Conference and Exhibition on Natural Gas Vehicles.

Ghobadian, B., Najafi, G., \& Nayebi, M. (2013). A semi-empirical model to predict diesel engine combustion parameters. Journal of Mechanical Engineering and Sciences, 4, 373-382.

Heywood, J. B. (1988). Internal combustion engine fundamentals. . New York: : McGraw-Hill.

Johnstone, N., \& Karousakis, K. (1999). Economic incentives to reduce pollution from road transport: The case for vehicle characteristics taxes. Transport Policy, 6, 99-108.

Mat Yasin, M. H., Mamat, R., Sharma, K. V., \& Yusop, A. F. (2012). Influence of palm methyl ester (pme) as an alternative fuel in multicylinder diesel engine. Journal of Mechanical Engineering and Sciences, 3, 331-339.

Moore, S. W., Rahman, K. M., \& Ehsani, M. (1999). Effect on vehicle performance of extending the constant power region of electric drive motors. . Paper presented at the SAE Technical Paper Series 1999-01-11.

Rahim, R., Mamat, R., Taib, M. Y., \& Abdullah, A. A. (2012). Influence of fuel temperature on a diesel engine performance operating with biodiesel blended. Journal of Mechanical Engineering and Sciences, 2, 226-236.

Roussillon, G. (1981). Contribution to accurate measurement of aerodynamic drag on a moving vehicle from coast-down tests and determination of actual rolling resistance. Journal of Wind Engineering and Industrial Aerodynamics :, 9, 3348.

Shimizu, K., Ikeya, C., \& Miyagi, M. (1988). Onboard measurement of road inclination. Measurement, ,(6), 87-93.

Smith, R., Morison, M., Capelle, D., Christie, C., \& Blair, D. (2011). Gps-based optimization of plug-in hybrid electric vehicles' power demands in a cold weather city. Transportation Research Part D: Transport and Environment, 16. 
Soon, L. B., Rus, M., Anika, Z., \& Hasan, S. (2013). Continuous biodiesel production using ultrasound clamp on tubular reactor. International Journal of Automotive and Mechanical Engineering, 8, 1396-1405.

Sundar Raj, C., \& Sendilvelan, S. (2010). Effect of oxygenated hydrocarbon additives on exhaust emission of a diesel engine. International Journal of Automotive and Mechanical Engineering, 2, 144-156.

Tzirakis, E., Pitsas, K., Zannikos, F., \& Stournas, S. (2006). Vehicle emissions and driving cycles: Comparison of the athens driving cycle (adc) with ece-15 and european driving cycle (edc). . Global NEST Journal 8,, 282-290.

Wu, C., Zhao, G., \& Ou, B. (2011). A fuel economy optimization system with applications in vehicles with human drivers and autonomous vehicles. Transportation Research Part D: Transport and Environment, 16, 515-524.

Yusaf, T., Hamawand, I., Baker, P., \& Najafi, G. (2013). The effect of methanol-diesel blended ratio on ci engine performance. International Journal of Automotive and Mechanical Engineering, 8, 1385-1395. 